\title{
Potensi longsor gunung gumitir sebagai dampak pengalihan fungsi lahan menjadi perkebunan kopi
}

\author{
Jamalludin $^{1)^{*}}$, Sudarti $^{1)}$, Wachju Subchan ${ }^{1)}$ \\ ${ }^{1)}$ Univesitas Jember \\ *masjamalludin6@gmail.com
}

Abstrak: Tanah longsor merupakan bencana alam yang sering terjadi di Indonesia, hal ini disebabkan oleh susunan tanah, kemiringan dan penahannya. Alih fungsi lahan semakin memperbesar intensitas terjadinya tanah longsor suatu daerah. Penelitian ini bertujuan untuk mengetahui potensi longsor akibat penanaman kopi pada lereng gunung. Metode penelitian yang digunakan dalam penelitian ini yaitu penelitian deskriptif dengan teknik pengumpulan data observasi dan kajian literature. Dihasilkan bahwa tanaman kopi pada lereng gunung gumitir memiliki dampak terhadap potensi longsor di daerah tersebut.

Kata Kunci: Tanah Longsor, alih fungsi lahan, dan tanaman kopi.

\section{Pendahuluan}

Tanah longsor merupakan bencana alam yang sering terjadi di Indonesia. Badan Nasional Penanggulangan Bencana (BNPB) mencatat bahwa tanah longsor merupakan bencana alam no 3 yang sering terjadi diinonesia, dimana sejak 1 januari sampai 18 juni 2021 telah tercatat 293 kejadian tanah longsor di berbagai daerah Indonesia. Dalam kurun waktu 3 tahun BNPB juga mencatat bahwa telah terjadi 10246 kejadian tanah longsor di Indonesia dan 843 diantaranya terjadi di jawa timur. Kabupaten banyuwangi sebagai salah satu kabupaten di jawa timur yang memiliki kontur alam pegunungan dan daratan rendah memiliki andil dalam menyumbang kasus bencana alam di jawa timur khususnya tanah longsor. Menurut (Nusantara \& , Setianto, 2015) tanah longsor terjadi secara terus menerus dari tahun ke tahun dan sebagian besar menimbulkan banyak kerugian sehingga perlu adanya perhatian khusus terhadap bencana ini. Banyaknya kasus tanah longsor diatas dapat menjadi cerminan bahwa bencana ini sangat sering terjadi di Indonesia.

Salah satu wilayah yang sering terjadi longsor di kabupaten banyuwangi yaitu gunung gumitir. Kerentanan longsor dikabupaten banyuwangi dipengaruhi oleh susunan bebatuan vulkanik muda dan dipengaruhi oleh litologi alluvium dengan dipicu oleh tingginya aktivitas manusia (Kurnianto, Elfiani, \& Alfani, 2021). Penebangan pohon dan alih fungsi lahan hutan menjadi perkebunan merupakan salah satu bentuk aktivitas manusia yang disinyalir memiliki dampak dan memperbesar kemungkinan terjadinya tanaha longsor. Hal didukung oleh pendapat Ni Made Dwi Pradnyasari \& Kusmawati (2019) yang mengatakan bahwa kerentanan suatu lereng terhadap tanah longsor dipicu oleh dua factor yaitu oleh alam sendiri karena susunan batuan dan aktivitas manusia (berupa penebangan liar dan alih fungsi lahan). Menurut (Yongki Kurniawan, Dedy Miswar, 2018) kejadian tanah longsor pada suatu daerah merupakan indikasi terjadi kerusakan pada derah tersebut sehingga tanah menjadi bergerak kebawah. Berdasarkan beberapa pendapat tersebut dapat kita pahami bahwa kondisi tanah, dan aktivitas manusia dapat menyebabkan terjadinya tanah longsor.

Tanah longsor biasa terjadi pada lereng pegunungan yang memiliki kecuraman tertentu. Menurut (Ramadhani \& Idajati, 2017) longsor di indonesia terjadi pada topografi terjal yaitu dengan kemiringan $15^{0}-$ $45^{0}$ pada curah hujan tinggi. Selain factor topografi berupa kemiringan tanah factor jenis tanah pernyusun juga memperngaruhi hal ini didukung oleh (Apriyono, 2009) yang menyatakan bahwa jenis tanah yang memiliki nilai kohesi kecil akan memperbesar kemungkinan terjadinya tanah longsor. keberadaan pepohonan pada lereng gunung memperkecil kemungkinan terjadinya tanah longsor akan tetapi alih fungsi lahan pohon yang kuat menahan lomgsor dengan tanaman budidaya memperbesar kemungkinan tanah longsor hal ini didukung oleh (Naryanto, Soewandita, Ganesha, Prawiradisastra, \& Kristijono, 2019) yang menyatakan bahwa pemanfaatan lereng gunung dengan tanaman budidaya dapat menyebabkan ketidak stabilan lereng. 
Letak gunung gumitir yang berada diantara Kabupaten Jember dan Banyuwangi menyebabkan pegunungan ini menjadi jalur transpirtasi umum. Sepanjang jalur yang dilalui kendaraan, terlihat tanaman kopi yang relative muda banyak menggantikan pohon-pohon besar tanaman asli di pegunungan ini. Intensitas tanah longsor yang sering terjadi belum menyadarkan masyarakat bahwa akibat alih fungsi lahan yang dilakukan dapat membahayakan pengguna jalur. Untuk mengetahui apakah tanaman kopi dilereng pegunungan gumitir menjadi penyebab tingginya intensitas tanah longsor di jalur tersebut. Oleh karena itu dilakukan penelitian dengan judul analisis dampak penanaman kopi pada lereng gunung gumitir kabupaten banyuwangi. Penelitian ini bertujuan untuk mengindetifikasi pengaruh penanaman kopi dilereng gunung terhadap intensitas tanah longsor di gunung gumitir.

\section{Metode}

Metode yang digunakan pada penelitian ini yaitu metode deskriptif, dengan teknik pengumpulan data observasi dan kajian literatur. Subjek penelitian yaitu sepanjang jalur transportasi banyuwangi-jember di pegunungan gumitir. Identifikasi daerah rawan longsor berdasarkan kemiringan lereng, struktur lapiran batuan dan tanaman kopi yang berada di lereng.

\section{Hasil dan Pembahasan}

Penelitian di awali dengan mengumpulkan data banyaknya kasus terjadinya tanah longsor di gunung gumitir dengan mengumpulkan kajian tanah longsor yang sudah terekam pada berita. Berdasarkan penelusuran penulis didapatkan hasil bahwa dalam kurun waktu 5 tahun terakhir telah terjadi 19 kasus tanah longso yang menyebabkan kemacetan panjang. Dimana 2 terjadi pada tahun 2017, 6 terjadi tahun 2018, 3 terjadi 2019, 3 terjadi tahun 2020 dan 5 terjadi 2021. Setiap peristiwa tanah longosr yang terjadi pada lereng gumitir tersebut menyebabkan kemacetan yang sangat panjang, bahkan mencapai $20 \mathrm{~km}$. kasus terakhir yang terjadi yaitu tanggal 20 bulan November 2021, dimana lanang losong sekaligus diikuti dengan pohon timbang yang menimpa pengendara mobil yang sedang melintas. Berdasarkan berita kejadian tanah longsor 5 tahun terakhir rata-rata terjai pada $\mathrm{km} 35$ sampai $\mathrm{km} 37$ hal ini sesuai dengan pendapat (Prawira, 2014) yang menyatakan bahwa pada km 34-37 pada lereng gunung gunung gumitir merupaka daerah yang memiliki tingkat rentan longsor yang tinggi. Terlepas dari adanya korban jiwa atau tidak rentetan peristiwa diatas jelas membahayakan dan menghambat pengguna jalan yang melintasi jalur gumitir ini.

Pengumpulan data berikutnya dilakukan dengan observasi lapangan dan analisis data secara virtual. Observasi secara virtual dilakukan menggunakan google eart, Penggunaan google eart dilakukan oleh peneliti untuk mendapatkan gambaran muka pegunungan tampak dari ketinggian. Secara vitual tampak jalur gunung gumitir di lakukan citra dari atas seperti pada gambar 1 berikut.

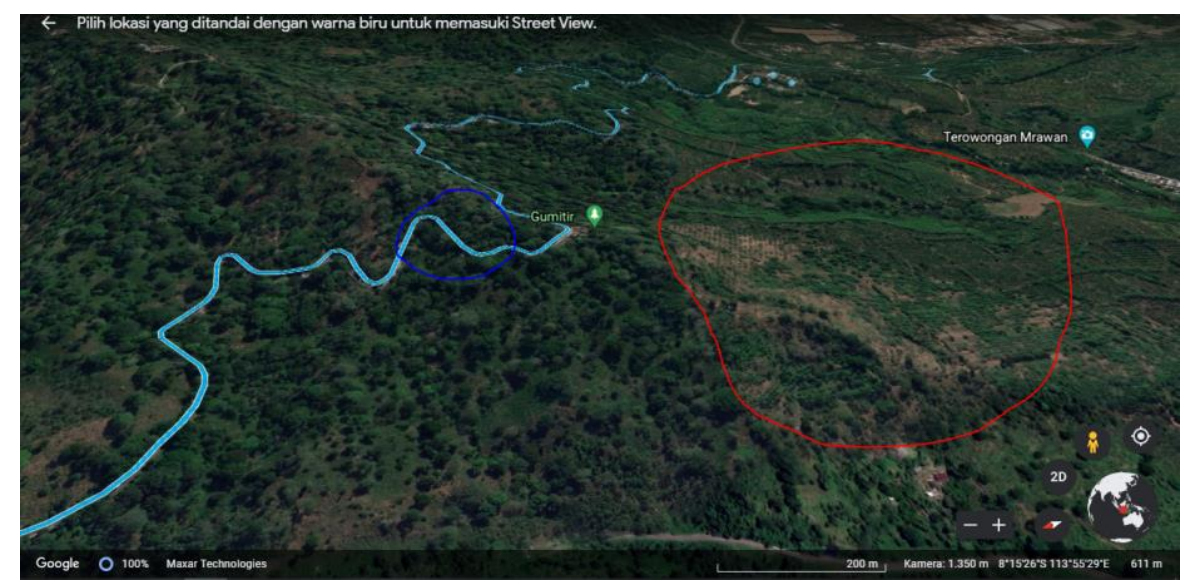

Gambar 1. Tampa katas lahan gunung gumitir.

Penggunaan googele eart dipilih peneliti karena dapat mencitra suatu lahan daeri atas. Menurut (Zaki, 2010) data pada google eart merupakan gabungan dari gambar fotografi udara dan gambar satelit sehingga gambar yang dihasilkan kaulitasnya bagus, dan mampu merilis gambarnya secara kontinu. Penggunaan google aert ini dimaksudkan untuk mendapatkan gambaran lahan gunung gumitir dari ketinggian yang menyebabkan tingginya kasus tanah longsor di jalur tersebut. Berdasarkan data yang tampak pada gambar 1 Dapat dilihat 
bahwa pepohonan yang rimbun hanya di sekitar jalur transportasi, selebihnya lahan telah di alih fungsikan menjadi lahan pertanian milik warga. (Harijanto, 2019) menjelaskan bahwa alih fungsi lahan lereng pegunungan menjadi tegalan / perkebunan budidaya meningkatkan erosi lahan pada daerah tersebut. Pada lahan yang dilakukan penanaman kopi dihutan secra tumpeng sari atau agroforesti menyebabkan nilai erosi pada lahan tersebut meningkat (Meylina et al., 2015). Oleh karena itu alih fungsi lahan yang dilakukan petani lereng gunug gumitir berpotensi menjadi pemicu longsor yang sering terjadi sepanjang lereng gunung gumitir.

Tabel 2. Hasil Observasi
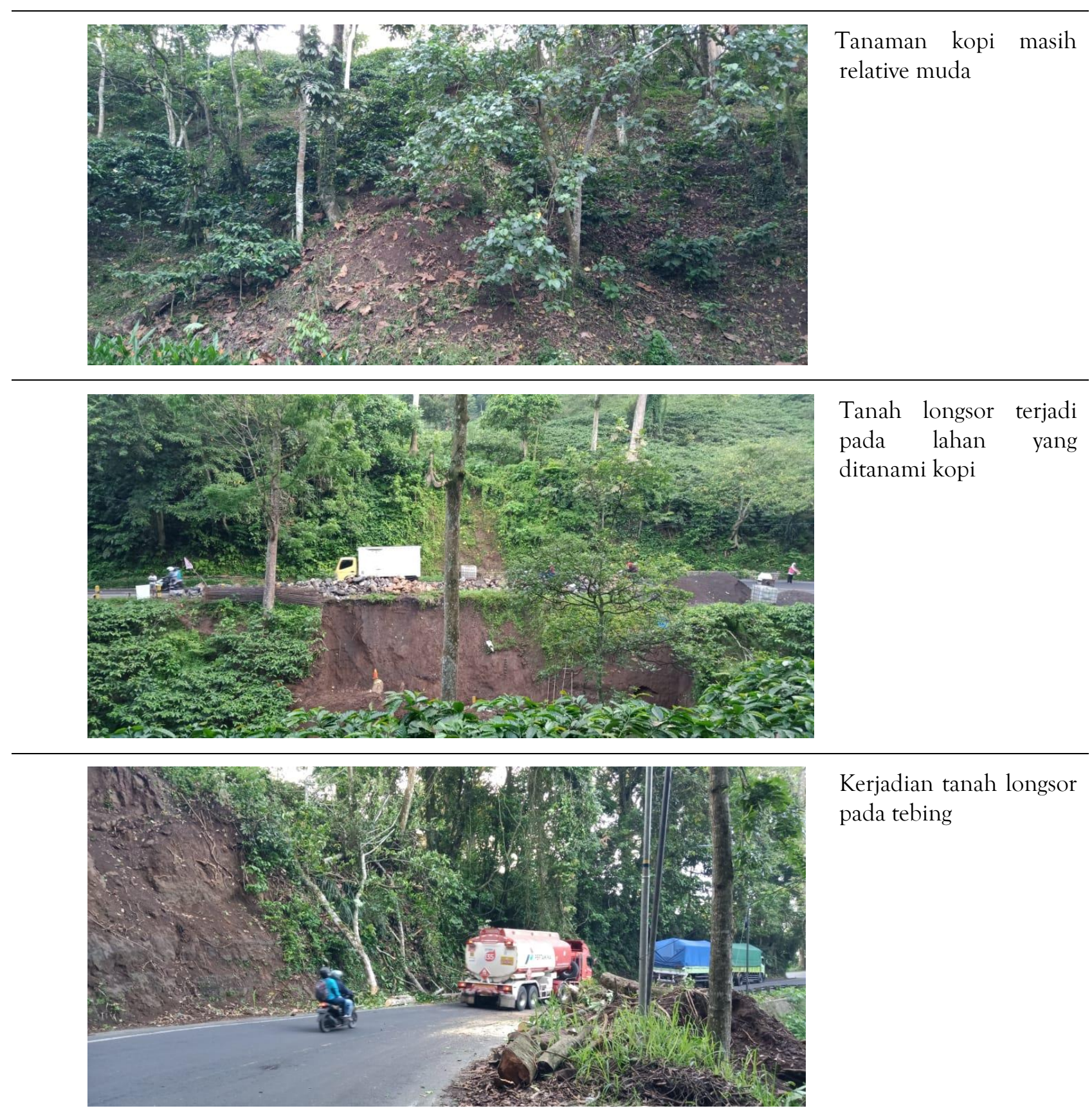

Kerjadian tanah longsor pada tebing

Berdasarkan observasi lapangan tanaman kopi yang berada di lereng gunung gumitir masih relative muda, sehingga memperbesar kemungkinan terjadinya tanah longsor di sekitar lereng gunung. Penanaman kopi pada lereng gumitir bisa dikategorikan dalam dua tipe tanam yaitu monokultur dan agroforestry. Menurut (Banuwa, 2013) penanaman kopi monoculture meningkatkan erosi tanah sebesar $33 \%$. Penanaman kopi dengan agroforestry menyebabkan penurunan ketebalan resahan tanah, dan akan semakin berkurang jika dilakukan secara monokultur (Hairiah et al., 2004). Meskpun terjadi penurunan pada penanaman agroforestry akan tetapi masih lebih baik dari pada mononkulture. Pada lereng gunung gumitir tidak semua secara agroforestry terlihat pada gambar bahwa beberapa lahan dilakukan secara monoculture sehingga erosi pada beberapa lereng curam 
sangat tinggi. Pada hasil observasi terlihat bahwa tanah yang longsor hanya pada daerah yang ditanami kopi, pada pohon yang relative besar kondisi tanah masih relative tertahan sehingga tidak mengakibatkan longsor.

Selain kondisi lereng yang curam kondisi tanah penyusun gunung gumitir juga menjadi penyebab terjadinya tanah longsor. Menurut (Aries Suyandra Eko Cahyono, Indrasurya B.Mochtar, 2013) lereng gunung gumitir di susun oleh tanah lempung dan tanah berpasir. Hal ini juga didukung oleh hasil penelitian geologi di banyuwangi pada gambar 2 berikut.

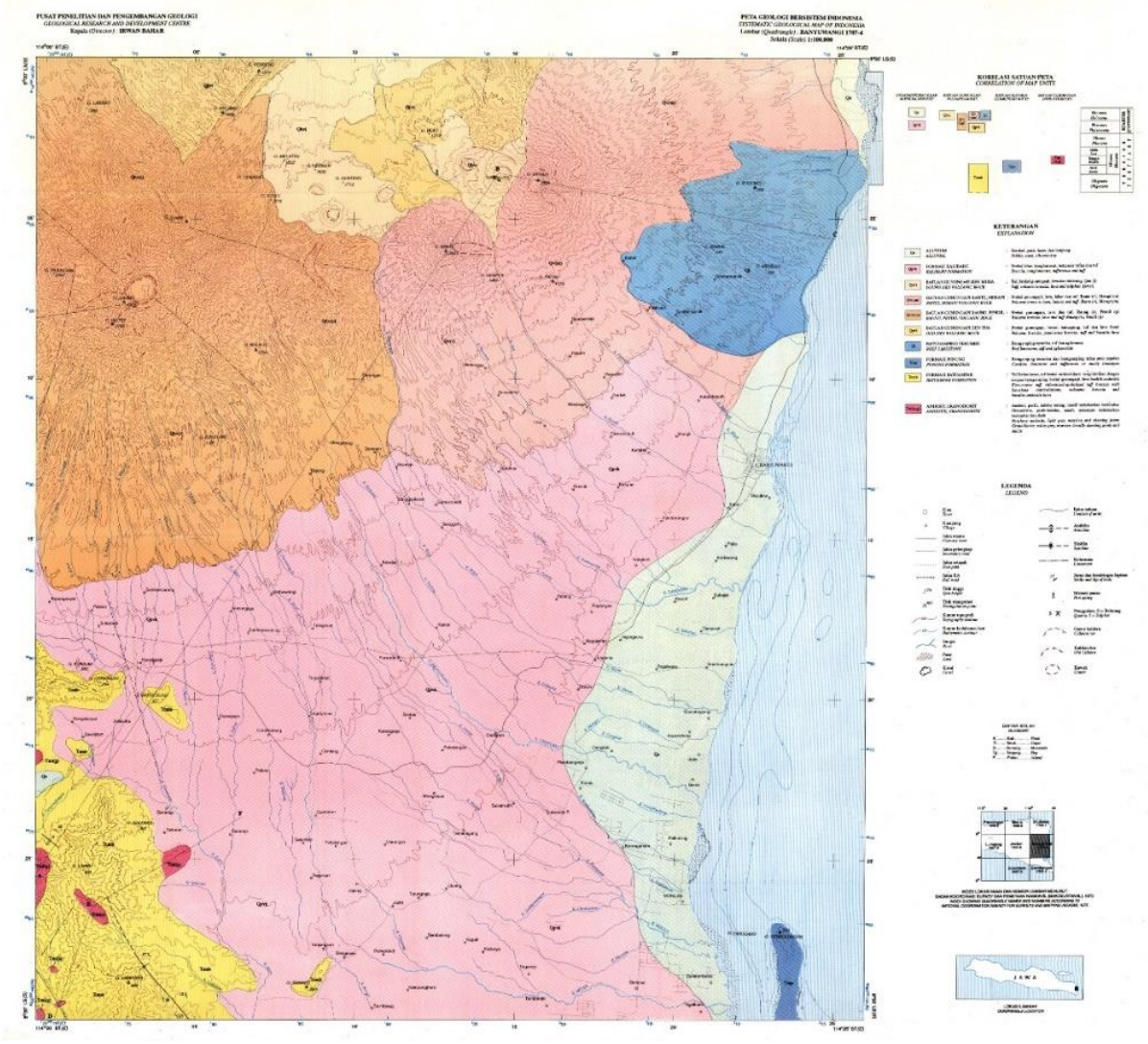

Gambar 2. Peta tanah banyuwagi.

Berdasarkan peta tanah yang ada dibanyuwangi, kalibaru tersusun atas tanah jenis breksi lahar, konglomerat, batu pasir, tufan dan tuf. Menurut (Hidayat, Jonson Sutanto, \& Deddy Munir, 2020) menyatakan bahwa batuan breksi andesit dan tufa dalam kondisi segar bersifat massif dan kedap air, sehingga kontak antara batuan dasar dan zona lapukan menyebabkan bidang gelincir longsoran. Akibat kondisi tersebut ketika hujan turun, air akan tertahan dalam tanah dan zona pelapukan menjadi lebih berat dan memperbesar potensi longsor. Untuk mengantisipasi terjadinya tanah longsor maka dilakukan penanganan tersetentu yang bertujuan agar air tidak tertahan dalam zona pelapukan, mengikat tanah, dan merembeskan air lebih dalam (Muhammad Wahyudinoor Fitriadi1, Rosalina Kumalawati1, 2017). Penanganan ini biasanya dilakukan dengan menggunakan pohon yang akarnya menjulang jauh kedalam tanah. Pennggaantian tanaman endemic dengan tanaman kopi yang akarnya tidak terlalu menjulang kebawah terbukti memperbesar kemungkinan terjadinya erosi, hal ini dikarenakan akar kopi tidak dapat mengikat tanah pada zona pelapukan, dan tidak dapat menembeskan air hujan yang diserap tanah menuju lebih dalam dari pada zona pelapukan.

\section{Simpulan}

Berdasarkan analisis literature dan observasi diketahui bahwa gunung gumitir rentan terhadap longsor karena kondisi lereng yang curam, tanah peyusunnya dan alih fungsi lahan dari tanaman endemic menjadi tanaman budidaya yaitu tanaman kopi. Teknik budidaya tanaman kopi baik mono culture atau agroforestry keduanya juga memperbesar terjadinya erosi pada lereng gunung gumitir karena jenis tanah yang ada pada lereng. Longsor yang terjadi pada lereng gunung terjadi pada lahan yang ditanami kopi dan lahan yang curam. 


\section{Daftar Pustaka}

Apriyono, A. (2009). Analisis Penyebab Tanah Longsor Di Kalitlaga Banjarnegara. Dinamika Rekayasa, 5(1), 1418.

Aries Suyandra Eko Cahyono, Indrasurya B.Mochtar, dan M. A. (2013). Perencanaan Perbaikan Lereng Longsor Pada Jalan Lintas Gunung Gumitir Ruas Jalan. ITS, 1-6.

Banuwa, rawan sukri. (2013). erosi. jakarta: PRENADAMEDIA GROUP.

Hairiah, K., Suprayogo, D., Widianto, Berlian, Suhara, E., Mardiastuning, A., ... Rahayu, S. (2004). Alih Guna Lahan Hutan menjadi Lahan Agroforestri Berbasis Kopi: ketebalan seresah, populasi cacing tanah dan makroporositas tanah. Agrivita, 26(1), 68-80. Retrieved from http://karyailmiah.fp.ub.ac.id/fp/wpcontent/uploads/2014/09/Agrivita-vol-26-no-1-Maret-2004_4.pdf

Harijanto, H. (2019). KAJIAN EROSI TANAH AKIBAT ALIH GUNA LAHAN DI DAS OLONJONGE KABUPATEN PARIGI MOUTONG SULAWESI TENGAH. J. ForestSains, 1(1), 105-112.

Hidayat, R., Jonson Sutanto, S., \& Deddy Munir, M. (2020). Kondisi Geologi Dan Pola Hujan Sebagai Pemicu Longsor Di Jawa Tengah Bagian Selatan Pada Juni 2016 Geological and Rainfall Condition As Landslide Causative Factors in Shoutern Part of Central Java in Juni 2016. Researchgate.Net, (February). https://doi.org/10.32679/jth.v7i2.565

Kurnianto, F. A., Elfiani, V., \& Alfani, A. F. (2021). Analisis Spasial Kerentanan Banjir dan Longsor di Kabupaten Banyuwangi. 6(1), 49-60.

Kusmawati, N. M. D. P. W. T. (2019). Pemetaan Potensi dan Kerawanan Longsor Lahan di Desa Belandingan, Desa Songan A dan Desa Songan B Kecamatan Kintamani , Kabupaten Bangli. Jurnal Agroekoteknologi Tropika, 8(2), 231-241.

Meylina, E., Wahyuningsih, S., Pudjojono, M., Teknik, L., Lingkungan, K., \& Pertanian, J. T. (2015). TEKNOLOGI PERTANIAN Estimasi Tingkat Erosi pada Sistem Tumpangsari Kopi - Tanaman Semusim Menurut Metode MUSLE ( Modified Universal Soil Loss Equation ) di Desa Pace Kecamatan Silo Kabupaten Jember Estimate of Erosion on Coffe Intercropping System - Crops. Berkala Ilmiah Teknologi Pertanian, 1(maret), 1-6.

Muhammad Wahyudinoor Fitriadi1, Rosalina Kumalawati1, D. A. (2017). TINGKAT KESIAPSIAGAAN MASYARAKAT TERHADAP BENCANA TANAH LONGSOR DI DESA JARO KECAMATAN JARO KABUPATEN TABALONG. JPG (Jurnal Pendidikan Geografi), 4(4), 32-41.

Naryanto, H. S., Soewandita, H., Ganesha, D., Prawiradisastra, F., \& Kristijono, A. (2019). Analisis Penyebab Kejadian dan Evaluasi Bencana Tanah Longsor di Desa Banaran, Kecamatan Pulung, Kabupaten Ponorogo, Provinsi Jawa Timur Tanggal 1 April 2017. Jurnal Ilmu Lingkungan, 17(2), 272. https://doi.org/10.14710/jil.17.2.272-282

Nusantara, Y. ., \& , Setianto, A. (2015). Pemetaan Bahaya Tanah Longsor dengan Metode Frequency Ratio di Kecamatan Piyungan dan Pleret, Kabupaten Bantul, Daerah Istimewa Yogyakarta. Seminar Nasional Kebumian Ke-8 15-16 Oktober 2015; Grha Sabha Pramana. 15-16 OKTOBER 2015; GRHA SABHA PRAMANA.

Prawira, A. E. (2014). TINGKAT KERENTANAN BENCANA LONGSOR PADA JALUR GUNUNG GUMITIR (JALAN PENGHUBUNG KABUPATEN BANYUWANGI DAN KABUPATEN JEMBER)1. Respository UM, 3, 103-111. Retrieved from http://repository.um.ac.id/53231/

Ramadhani, N. I., \& Idajati, H. (2017). Identification of the Landslide Hazard Level, Case Study: Mount Lawu Slope Area, Karanganyar Regency, Central Java. Jurnal Teknik ITS, 6(1), 87-90.

Yongki Kurniawan, Dedy Miswar, I. L. N. (2018). Pemetaan Daerah Rawan Longsor di Kecamatan Sumber Jaya Kabupaten Lampung Barat Tahun 2017. Jurnal Penelitian Geografi, 6.

Zaki, A. (2010). Keliling Dunia dengan Google Eart + Google Map (1st ed.). Semarang: SMITDEV. 